\title{
Estado del arte en los aspectos científicos, tecnologicos nutricionales y de ingeniería de los agentes probióticos y prebioticos
}

\author{
${ }^{1}$ Mondragón B., Olga; ${ }^{2}$ Maugeri, Francisco \\ ${ }^{1}$ Especialización en Ingeniería de Procesos en Alimentos y Biomateriales. \\ Universidad Nacional Abierta y a Distancia UNAD. E-mail: \\ olgalumondragon@hotmail.com \\ ${ }^{2}$ Faculdade de Engenharia de Alimentos FEA- Universidade Estadual de Campinas - \\ UNICAMP.
}

\begin{abstract}
Resumen
Alimentos que contienen pro y pre-bióticos se denominan simbióticos, estos benefician la salud manteniendo el balance de la flora intestinal, reduciendo la mala absorción de la lactosa, aumentando la protección contra infecciones intestinales, entre otros. Los probióticos y pre-bióticos son productos funcionales y nutracéuticos, los primeros se definen como "microorganismos vivos con capacidad de mejorar el equilibrio microbiano intestinal produciendo efectos benéficos para la salud del individuo" y los pre-bióticos son ingredientes alimenticios no digestibles y que selectivamente favorecen el crecimiento de bacterias benéficas. Los ingredientes alimentarios que cumplen con los requisitos de prebióticos, hasta el momento, son los oligosacáridos. Bacterias probióticas presentan sitios de acción diferente en el sistema digestivo (p.e. Lactobacillus actúan en el intestino delgado, mientras que bifidobacterias actúan en el intestino grueso). La reintroducción de estos grupos microbianos en el hospedero es hecha por medio de la administración de especies seleccionadas, que deberán estar en números elevados y viables en el momento de su consumo. Algunos aspectos técnicos son comunes en la producción de cualquier tipo de leche o bebida fermentada, como son: (i) tipo de organismos que constituyen el cultivo starter, (ii) temperatura, presencia de oxígeno y período de incubación, (iii) la proporción del inóculo, (iv) la producción del starter, y, (v) los factores de crecimiento.
\end{abstract}

Palabras claves: Pró-bióticos, Pré-bióticos, Simbióticos, Bifidobacterias, Lactobacilos, Oligosacáridos.

\begin{abstract}
Foods that contain pro and pre-biotic denominate symbiotic, these benefit the health maintaining the balance from the intestinal flora, reducing to the bad absorption of the lactose, increasing the protection against intestinal infections, among others. The probiotic and pre-biotic are functional products and nutraceutics, first they are defined as "alive micro organisms with capacity to improve the intestinal microbial balance producing beneficial effects for the health of the individual" and the pre-biotic are non digestible nutritional ingredients and that selectively favour the growth of beneficial bacteria. The nourishing ingredients that fulfil the requirements of pre biotic, until the moment, are the oligosaccharides ones. Pro biotic bacteria present/display sites of different action in the digestive system (Lactobacillus acts in the thin intestine, whereas bifid bacteria acts in the heavy intestine). The re-introduction of these microbial groups in the lodging is done by means of the administration of selected species, which will have to be in high and viable numbers at the moment of their consumption. Some technical aspects are common in the production of any type of milk or fermented drink, as they are: (i) type of organisms that constitute the culture to starter, (ii) temperature,
\end{abstract}


oxygen presence and period of incubation, (iii) the proportion of inoculo, (IV) the production of starter, and, (v) the growth factors.

Key words: Pre-biotic, pre-biotic, symbiotic, bifid bacteria, lacto bacillus, oligosaccharides.

\section{Introducción}

La dieta es un tema que hoy en día es el mayor foco estratégico en lo relacionado a salud pública, pues tiene por objetivo la manutención de una óptima salud a través de la vida, previniendo la aparición temprana de enfermedades crónicas como los desordenes gastrointestinales, cardiovasculares, cáncer, osteoporosis, así como, la procura de promotores de salud para la población de la tercera edad.

A pesar de las muy complejas relaciones entre alimentos y salud, que aún son poco comprendidas, recientes investigaciones en diversas áreas, muestran nuevos aprovechamientos que prometen mejorar la comprensión del tema como es el caso de la creciente demanda de alimentos ‘saludables', que estimula la innovación y el desarrollo de nuevos productos en la industria de alimentos, nacional e internacionalmente.

Continuamente se incrementa el número de consumidores con conciencia de salud, en algunos casos por factores socio-económicos como la expansión europea y en otros por el interés mundial que se ha despertado por los alimentos funcionales.

Desde el tiempo de Metchnikoff (el primeiro que relacionó salud con el consumo regular de leches fermentadas, en el siglo XIX), se sabe que una flora intestinal balanceada es importante para la salud y bienestar del hombre (Tamine, 1995).

Recientemente se ha tenido un gran avance en el desarrollo de los productos llamados probióticos (productos que contienen microorganismos vivos capaces de beneficiar al hombre en algún aspecto, especialmente regulando la flora intestinal)

Trillones de bacterias de mas de 400 especies diferentes, saprofitas y patogénicas, viven harmoniosamente en un delicado balance en el tracto gastrointestinal, hasta que este sea desequilibrado por la dieta, consumo de drogas, situaciones de estrés, tratamientos quimioterapéuticos, edad y otras situaciones, provocando diferentes tipos de problemas gastrointestinales como la Disbiosis Intestinal, definida como un desorden en el tracto gastrointestinal, debido al desequilibrio de las bacterias intestinales (Carvalho, 2001).

Se sabe que, en diferentes regiones del tracto intestinal, están presentes grupos específicos de microorganismos, como bacterias lácticas y bífidas, que modulan la microflora en estos espacios, principalmente debido a los productos de su metabolismo (Ferreira y Teshima, 2000).

Esa microflora deseable protege al hospedero antagonizando el crecimiento de microorganismos patógenos, además de mantener su salud, impidiendo la reabsorción de compuestos aminados indeseables, desconjugando ácidos biliares, biodisponibilizando minerales como calcio y hierro, efecto positivo en cáncer, disminución de enfermedades coronarias, ayuda digestiva, efectos nutricionales, estimulación inmune, actividad antitumoral, actividad antimutagénica.

(Ouwehand,A.,1998), y, por medio de sus enzimas, favoreciendo el metabolismo de algunas sustancias como la lactosa, en individuos lactasa no persistentes (Salminen, 1999). 
El intestino humano constituye un complejo ecosistema de microorganismos. La población bacterial en el intestino delgado es muy alta y alcanza un recuento máximo de $10^{12} \mathrm{UFC} / \mathrm{g}$, en el intestino grueso el recuento de bacterias es de $10^{8}-10^{12} \mathrm{UFC} / \mathrm{g}$, en el intestino delgado es considerablemente mas bajo, $10^{4}-10^{8} \mathrm{UFC} / \mathrm{g}, 10^{6}-10^{7}$ al final del ileón (Fooks, et al., 1999) mientras que en el estómago solamente se encuentran de $10^{1}-10^{2}$ UFC/g, debido al bajo $\mathrm{pH}$. Recuentos de $10^{10}-10^{11} \mathrm{UFC} / \mathrm{g}$ de Bifidobacterias es común en heces de bebés alimentados con leche materna, representando el $80 \%$ de las bacterias intestinales (Gimenez, 2002). Bebés alimentados con biberón, normalmente tienen recuentos de 1 -log menos de bifidobacterias $\left(10^{9}-10^{10} \mathrm{UFC} / \mathrm{g}\right)$. en las muestras de heces que los bebes amamantados por la madre, y hay una tendencia para los bebés de biberón a tener niveles más altos de enterobacterias, estreptococos y otras bacterias putrefactivas.

\section{Importancia de los probióticos}

Según Ferreira, et al. (2000), en las últimas décadas las enfermedades intestinales que provocan diarreas han aumentado, siendo la mayor causa de su origen el empleo creciente de antibióticos de última generación con amplio espectro de actuación.

Estos antibióticos, además de eliminar el agente biológico para el cual la droga es direccionada, eliminan también microorganismos benéficos, causando disturbios en la microbiota intestinal del hospedero. Como resultado, microorganismos como Clostridium difficile, resistentes a la mayoría de los antibióticos, aumentan en número, y sus toxinas son las responsables de la mayoría de diarreas. Enterococcus y Eschericchia coli son otros grupos microbianos que causan problemas en pacientes hospitalizados, debido a la resistencia adquirida.

Algunos de los factores que afectan la composición de la microflora humana, enumerados por Fooks, et al. (1999), son: el tipo de alimentación, la cantidad, composición química y disponibilidad de sustancias de crecimiento, disponibilidad de sitios de colonización, interacciones inmunológicas, estrategias de fermentación individual por cada bacteria, el tiempo de tránsito intestinal, el pH intestinal, el potencial de oxidoreducción, disponibilidad de aceptores de electrones inorgánicos, producción de metabolitos bacterianos, presencia de compuestos antimicrobianos, edad del hospedero y movimientos peristálticos, entre otros.

Las principales especies que han sido empleadas para fines probióticos son bacterias del género Lactobacillus como Lactobacillus acidophilus, Lactobasillus casei, lactobacillus rhamnosus. Estirpes de Enterococcus spp. y Bacillus spp también han sido utilizados en la composición de algunos probióticos, además de Bifidobacterium. (Ferreira, et al. , 2000)

Para ser efectivos, los microorganismos probióticos deben ser rigurosamente seleccionados: I) origen humana, II) resistencia a los jugos gástricos, III) capacidad de adherencia a la mucosa intestinal, IV)resistencia a la bilis, V) resistencia a la lisozima, VI)*persistencia en el tracto intestinal humano VII)*producción de sustancias antimicrobianas, VIII)*Antagonistas de bacterias patogénicas y carcinogénicas, IX)*seguros para uso clínico y alimenticio, X)el producto, en el momento de su consumo, deberá contener números elevados de microorganismos probióticos y, para esto, deberá resistir las condiciones de procesamiento (deshidratación, congelación, liofilización), XI)*clínicamente validados y efectos sobre la salud documentados. (Fooks, et al., $1999 \mathrm{y} *$ Saarela, et al, 2000). 
La Tabla 1 muestra bacterias lácticas que han sido usadas en preparaciones de probióticos solas o en combinación.

Tabla 1. Ejemplos de bactérias acidolácticas para consumo humano ${ }^{1}$.Probióticos ${ }^{4}$

\begin{tabular}{|c|c|c|c|}
\hline Lactobacilli $^{2}$ & Bifidobacteria $^{2}$ & Streptococci & Enterococci \\
\hline $\begin{array}{l}\text { L. delbrueckii subsp } \\
\text { Bulgaricus }\end{array}$ & Bif. Bifudum & S. thermophilus & Ent. faecalis \\
\hline . acidophilus & Bif. Longum & & Ent. Faecium \\
\hline . rhamnosus & Bif. Breve & & \\
\hline salivarius & Bif. Infantis & & -actococcus lactis \\
\hline L. johnsonii & Bif. Adolescentis ${ }^{3}$ & & \\
\hline L. crispatus & Bif. Lactis ${ }^{3}$ & & \\
\hline L. reuteri & & & \\
\hline L. casei subsp. Casei $^{3}$ & & & \\
\hline L. casei biovarShirota ${ }^{3}$ & & & \\
\hline
\end{tabular}

${ }^{1}$ Tomado de Fooks, L. (1999), ${ }^{2}$ Mc. Cartney, Wenzhi e Tannock (1996), ${ }^{3}$ Tamine (1997). ${ }^{4} \operatorname{Saxelin}(1999)$

En 1987, Mitsuoka propuso un esquema hipotético en el cual se ilustran las interacciones entre las bacterias intestinales y la salud humana, como se muestra en la Figura 1. Las bacterias intestinales fueron clasificadas en tres categorías: las llamadas maléficas, benéficas, y neutrales con respecto a la salud humana.

Una lista de los principales efectos benéficos terapéuticos atribuidos al consumo de probióticos, según Fuller (1989, Ibid, Lourens-Hattingh, et al. 2001) son:

\section{Efectos benéficos}

Manutención de la microflora intestina normal

Antagonista de crecimiento de patogénicos

Estimulación del sistema inmunológico

Reducción de la intolerancia a la lactosa

Reducción de los niveles de colesterol sereo

Impiden la reabsorción de compuestos aminados indeseables

Desconjugación de ácidos biliares

Disminución de enfermedades coronarias

Actividad antimutagénica

Actividad anticarcinogénica

Actividad antitumoral

Mejora el valor nutricional de los alimentos

Efectos nutricionales

Aplicaciones terapeúticas

Prevención de infección urogenital

Alivia la constipación

Protección contra diarrea de los viajeros

Prevención de diarrea infantil

Reducción de diarrea inducida por antibióticos

Prevención de hipocolesterimia

Prevención contra cáncer de colon e vejiga

Prevención de la osteoporosis.

Factores que afectan la viabilidad de los probióticos 
La supervivencia de las bacterias probióticas en el medio de fermentación, depende de las cepas usadas, la interacción entre especies presentes, las condiciones de cultivo, la composición química del medio (p.e. fuente de carbono), acidez final, contenido de sólidos, promotores e inhibidores del crecimiento, concentración de azúcares (presión osmótica), oxígeno disuelto (especialmente para bifidobacterias), nivel de inoculación, temperatura de incubación, tiempo de fermentación y temperatura de almacenamiento (Lourens-Hattingh, et.al., 2000).

\section{Factores de crecimiento}

Como argumenta Tamine, et al. (1995), los innumerables estudios de las bifidobacterias in vitro para lograr su desarrollo en leche y lograr altos números de células, han conducido a la descripción de muchos factores promotores de crecimiento, como el extracto de fracciones de metanol de células de Propionibacterium freudenreichii 7025 sobre B. adolescentis, o, ácidos grasos de cadena corta (formato, acetato, propionato y butirato) que también estimulan el crecimiento de bifidobacterias

Factor Bifidus 1: es un componente de la leche y el calostro, que consiste en glicoproteínas como $\mathrm{N}$-acetilglucosamina. La k-caseína humana o sus derivados de tripsina son promores de B. bifidum, la hidrólisis de la tripsina resulta en un glicomacropéptido que contiene azúcares como la glucosamina y galactosamina, los cuales tienen actividad de factor bífido. Un factor similar fue encontrado en el moco secretado por las glándulas salivares, el intestino delgado y el colon; contiene glicoproteínas con $\mathrm{N}$-acetilgalactosamina, N-acetilglucosamina y ácido salicílico.

Factor Bifidus 2: La glicoproteínas de la leche y el suero parecen ser efectivas, y parecen ser péptidos no glicosilados de caseína, después de realizar hidrólisis con proteinasas.

Oligosacáridos: Han sido ampliamente estudiados por su habilidad promotora de crecimiento. La leche humana contiene una variedad compleja de oligosacáridos que pueden ser los responsables del crecimiento de B. bifidum, la especie predominante en las heces de bebés alimentados con leche materna.

La soya contiene oligosacáridos prebióticos como rafinosa y estaquiosa que son promotores naturales del crecimiento de bifidobacterias.(Tamine, et al.,1995).

\section{Prebióticos}

"Un prebiótico es un ingrediente alimentario no digestible que afecta benéficamente al hospedero al estimular selectivamente el crecimiento y actividad de uno o más número limitado de bacterias en el colon, que pueden mejorar la salud del hospedero", dicen Gibson \& Roberfroid (1965 Ibid Fooks, et al. 1999, y Knorr, 1998). 


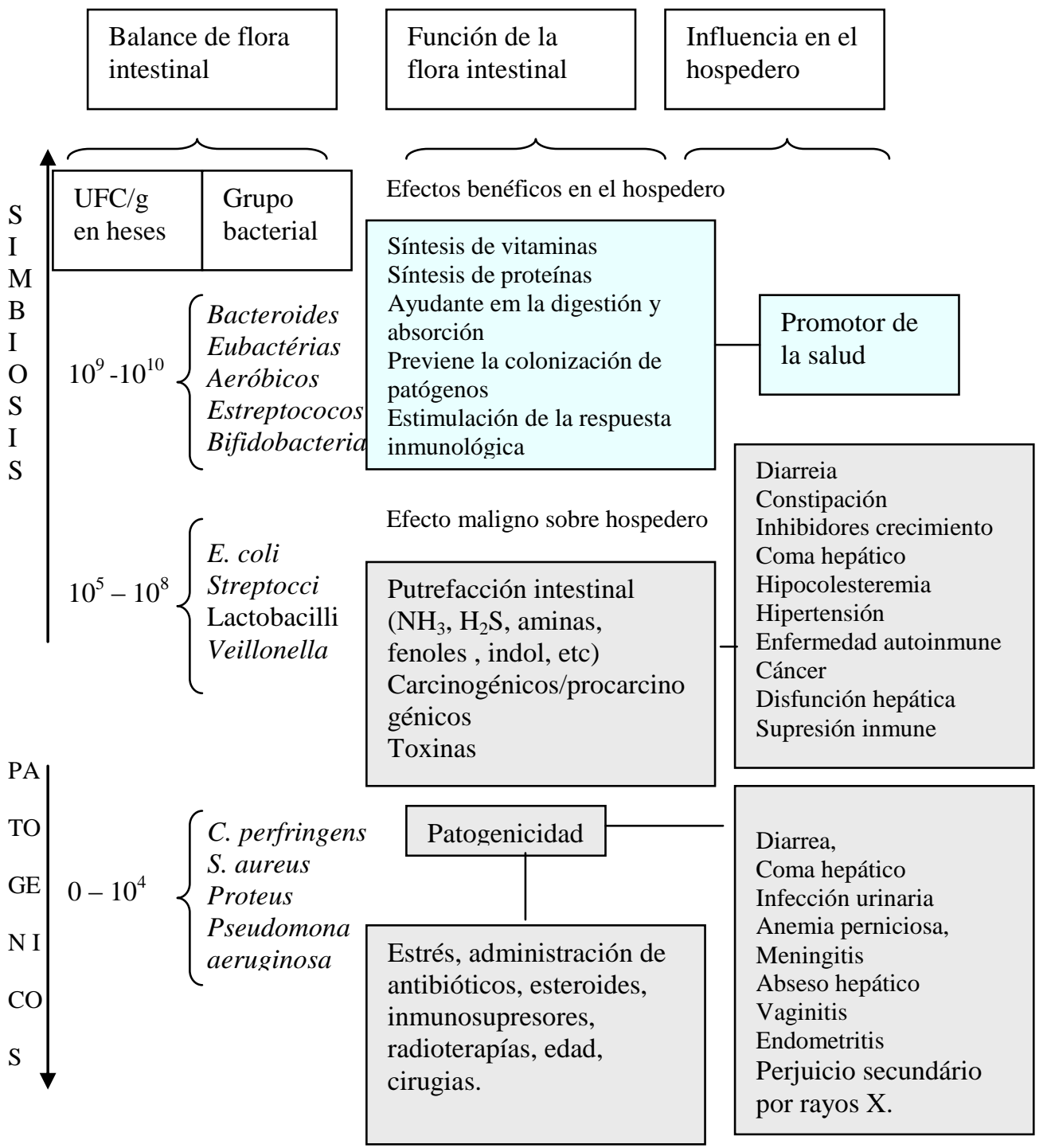

Figura 1. Correlaciones entre bacterias intestinales y salud humana propuesto por Mitsouka (tomado de Laurens-Hattingh, et al. 2001).

\section{Características de los prebióticos}

Conforme con lo descrito por Fooks, et al. (1999), el criterio para clasificación de los prebióticos como ingredientes alimentarios, incluye:

- No debe ser ni hidrolizado, ni adsorbido, en la parte superior del tracto gastrointestinal. 
- Fermentación selectiva por bacterias potencialmente benéficas en el colon, es decir, debe promover selectivamente el crecimiento y/o estimular la actividad metabólica de bacterias promotoras de la salud y no la de otras bacterias.

- Alteración en la composición de la microflora del colon a favor de una composición más saludable.

- Preferiblemente, inducir efectos que sean benéficos para la salud del hospedero.

Hasta hoy, los ingredientes alimentarios que cumplen con los requisitos de los prebióticos son los oligosacáridos, tales como los frutoligosacáridos (FOS), $\beta$-dfructanos, Gluco-oligosacáridos (GOS), Transgalacto-oligosacáridos (TOS), Isomaltooligosacáridos (IMO) e inulina. (Fooks et al.,1999). Los oligosacáridos son azúcares de tres a diez unidades de monosacáridos unidos por enlaces glicosídicos $\alpha(1$ 2) entre la fructosa terminal y la glucosa (Tamine et al. 1995), otros oligosacáridos presentes en algunos vegetales como las leguminosas son la rafinosa y estaquiosa que se caracterizan por ser indigeribles por el intestino humano y ser los causantes de algunos problemas digestivos como flatulencias.(Scalabrini y otros, 1998). La síntesis de oligosacáridos es muy estudiada y existen patentes japonesas, brasileras y europeas. La inulina, es una macromolécula oligosacárida, para la cual las bifidobacterias han demostrado tener actividad de inulinasa.

Los FOS están formados por una molécula de sacarosa, con una, dos o tres unidades de fructosa unidas glicosídicamente mediante enlace $\beta-(1-2)$ a la molécula de sacarosa (Figura 2).

Estos oligosacáridos derivados de la sacarosa son encontrados naturalmente en vegetales y plantas como alcachofa, raíz de chicoria, dalia, diente de león, cebolla, ajo y banano. Sin embargo, las concentraciones presentes son bajas, exigiendo un consumo muy elevado para la obtención de los efectos fisiológicos deseados (Ferreira, et al. 2000).

Los FOS presentan propiedades físicas y fisiológicas que los tornan unos compuestos de gran potencial de aplicación en alimentos para nutrición humana y animal. Son azúcares no digeribles por el organismo humano, que pasan a través del intestino delgado sin ser absorbidos y van directo para el intestino grueso, donde son selectivamente utilizados por las bifidobacterias de la microflora intestinal (U.S. Pat.:5.314.810).

\section{Producción de los Frutoligosacáridos (FOS)}

Según Maugeri \& Pinheiro (2002), el procerdimiento en medio acuoso es el siguiente:

Producción de la Inulinasa: El microorganismo Kluyverimyces sp.- es inoculado en el medio de cultivo constituido por sacarosa, extracto de levadura, peptona y $\mathrm{K}_{2} \mathrm{HPO}_{4}$, con $\mathrm{pH}$ ajustado entre $3,0-4,0$, e incubado a $30^{\circ} \mathrm{C}$ en un fermentador a $150 \mathrm{rpm}$ por $72 \mathrm{~h}$. La enzima extracelular es obtenida por centrifugación del caldo fermentado a $11.000 \mathrm{~g}$ durante 10 min a $4-6{ }^{\circ} \mathrm{C}$.

Recuperación de la enzima con etanol: el sobrenadante obtenido se utiliza para recuperar la enzima. La precipitación de la enzima es realizada por la adición de lenta de etanol a $-15{ }^{\circ} \mathrm{C}$ al sobrenadante, hasta alcanzar una saturación de $70 \%$ de etanol. En seguida se centrifuga a 11.000 g por 15 min. a $4-6{ }^{\circ} \mathrm{C}$. El sobrenadante es destilado para 
la recuperación del etanol y el precipitado es resuspendido en tampón de fosfato de sodio 0,05 $\mathrm{M}$ a pH 5,0.

Purificación de la Inulinasa: La enzima recuperada en etanol se purifica por cromatografía iónica. La solución enzimática resuspendida en tampón es filtrada, la columna es previamente lavada con tampón fosfato $0,1 \mathrm{M}$ a $\mathrm{pH} 6,0$, temperatura entre $15-20{ }^{\circ} \mathrm{C}$ y seguido de un gradiente salino ascendente de 0-90\%. El proceso es monitoreado a $280 \mathrm{~nm}$. Durante la elusión de la enzima, se colectan las fracciones y se determina la actividad enzimática.

Inmovilización de la Inulinasa: puede ser realizada en diferentes medios como en carbón activado junto con alginato de sodio como agente gelificante, sílica y glutaraldehido o alginato de cálcio. La mezcla se calienta hasta $80^{\circ} \mathrm{C}$, para que ocurra la disolución total del alginato. Luego se enfría a $40{ }^{\circ} \mathrm{C}$, se adiciona $2 \%$ de la solución enzimática con una concentración de $50 \mathrm{UI} / \mathrm{mL}$. Para la formación de las esferas, la solución es bombeada sobre una solución de Cloruro de Calcio 0,2 $\mathrm{M}$ en tampón de acetato $0,1 \mathrm{M}$ bajo agitación.
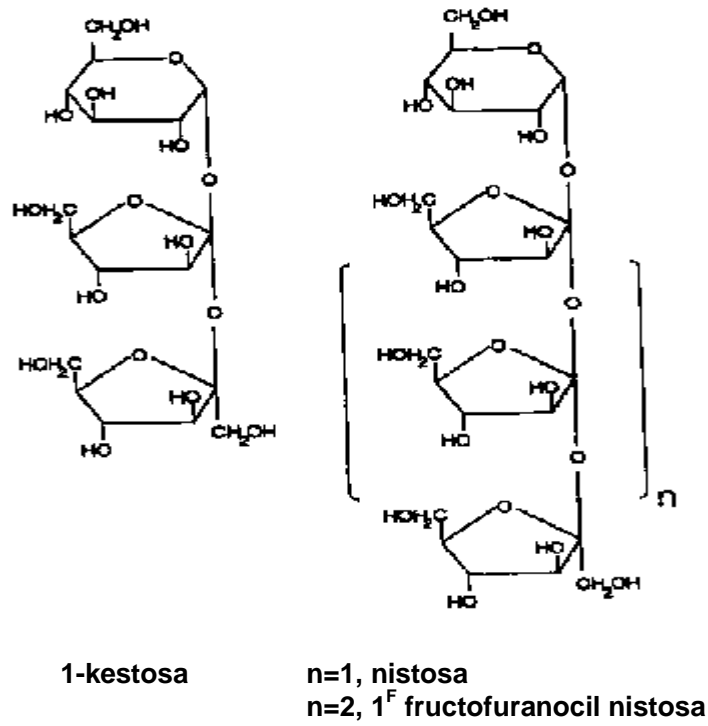

Figura 2. Estructura química de frutoligosacáridos (Yun,1996)

Producción del Jarabe de azúcares conteniendo glucosa, fructosa y FOS a partir de sacarosa: Una columna encamisada es rellenada con el biocatalizador, a una temperatura entre $35-50{ }^{\circ} \mathrm{C}$. La columna se alimenta con una solución de sacarosa entre 40 y $70 \%$ y $\mathrm{pH}$ de 5,0-6,5. La concentración de azúcares en la salida puede variar según las condiciones del proceso (concentración de alimentación, $\mathrm{pH}$, temperatura, concentración del biocatalizador, actividad enzimática, tiempo se residencia en la columna). El producto obtenido es apropiado para la industria de alimentos, productos funcionales, prebióticos y ricos en fibra soluble alimentaria.

Actualmente se adelantan otros estudios para la obtención de rutoligosacáridos en medio orgánico (Alves, 2002). 


\section{Simbióticos}

Los productos que contienen una bacteria probiótica (Lactobacilo y/o Bacteria bífida) y un prebiótico son llamados simbióticos (Roberfroid, 1998 Ibid Saarela, et al., 2000).

En el desarrollo de simbióticos es necesaria la selección de variedades con mejor capacidad de utilización de un determinado prebiótico, para que se obtenga un efecto sinérgico en la implantación y proliferación de las bacterias deseables (Ferreira, et al, 2000).

Según Saarela, et al. (2000), como el concepto de simbióticos es nuevo no existen muchos estudios específicos de la interacción entre pro y prebióticos. En general, las propiedades de los prebióticos pueden influenciar el crecimiento y supervivencia de los probióticos, afectando a su vez el crecimiento tanto de probióticos como de cultivos starter en conjunto. Esto lleva a tomar en consideración las interacciones entre probióticos y starters. La interacción in vivo puede ser favorecida para una adaptación del probiótico al prebiótico, condicionando su metabolismo simultáneamente con un substrato dado, resultando en una ventaja competitiva para el probiótico. Sin embargo, algunos estudios han mostrado que probióticos pueden crecer sin este tipo de adaptación.

La simbiosis se presenta también entre microorganismos de diferentes especies o géneros como es el caso de Lactobacillus casei y Lactobacillus acidophillus: estos microorganismos mantienen una relación de simbiosis, en la cual el segundo produce ácido butírico y ácido láctico que acidifican el medio y el L. casei consume estos metabolitos, manteniendo el $\mathrm{pH}$ entre 6 y 7 compatible para la supervivencia de las especies inoculadas. (USPat.6,033,691).

\section{Co-cultivos e interacción entre especies}

La supervivencia de L. acidophilus y especies de Bifidobacterium se ve afectada por las especies que participan en la fermentación, por causa de los metabolitos secretados por otros microorganismos. Dave y Shah (1997) reportaron que la inhibición de las bifidobacterias en yogurt no se debió a los ácidos orgánicos producidos o a la presencia de peróxido de hidrógeno, sino que se presume que la inhibición fue causada por los efectos antagónicos entre los cultivos starter. Gilliland and Speck (1977, ibid LaurensHauttingh, et al., 2001), en estudios realizados mostraron que sustancias producidas por L. bulgaricus causaban el decrecimiento de L. acidophilus durante el almacenamiento en refrigeración de yogurt; el peróxido de hidrógeno producido durante la manufacturación es la principal sustancia causante de este antagonismo, comprobado por el hecho de que al adicionar catalasa se disminuyó el efecto, L. acidophilus y B. bifidum (Laurens-Hauttingh, et al., 2001) presentan un efecto sinergístico promotor de crecimiento, puesto que el segundo depende de otra bacteria ácido láctica para asegurar su crecimiento.

Unas 17 especies de bifidobacterias crecen en leche pura y 15 tienen problemas para sobrevivir, por el hecho de tener escasa actividad proteolítica, precisando para crecer de la adición de caseína proteolíticas como los Lactobacilos que algunos autores catalogan como una dramática pérdida de la viabilidad del L. acipophilus, adicionalmente la 
sobreacidificación que causa L. bulgaricus durante el proceso y almacenamiento también afecta. Desde el punto de vista de Rybka \& Kailasapathy (1995), la presencia de L. bulgaricus es el principal responsable de la mortalidad de L. acidophilus y de Bifidobacterium ssp.

Especies de L. acidophilus viven en excelente simbiosis con bifidobacterias pues son capaces de proveerles estimulantes de crecimiento. La mezcla de cepas vivas de L. acidophilus y especies de Bifidobacterium usada en producción de bio-bebidas recientemente, es conocida como $\mathrm{AB}$-cultivos. La mezcla de $\mathrm{AB}$ cultivos con $\mathrm{S}$. termophilus produce los llamados productos fermentados ABT. (Vinderola, Reinheimer y otros, 2000).

\section{Tecnología de Producción}

La tecnología y la bioquímica de las fermentaciones, incluyendo los cambios físicoquímicos que pueden ocurrir en la leche durante la fabricación de yogurt y otros productos fermentados ha sido extensivamente investigada y revisada por muchos grupos de estudio. (Rasic \& Kurmman, 1983, 1992 ; Tamine \& Robinson, 1995, 2001, Dave \& Shah, 1997, Vinderola \& Reinheimer, 1999, 2000). Periódicamente, la International Dairy Federation publica monografías actualizadas de los aspectos científicos y tecnológicos en el campo de los lácteos y revisiones recientes de desarrollos tecnológicos para leches fermentadas, diseño higiénico de equipos de procesamiento de lácteos y mantenimiento de plantas de producción.

Sin embargo, los principales tópicos de producción de cualquier tipo de leche fermentada (p.e. estandarización del contenido de grasa, fortificación de los sólidos lácteos, homogenización, desaireación (opcional) y altos tratamientos térmicos) son comunes, así, aspectos técnicos que deben ser considerados en detalle, incluyen: los organismos que constituyen el cultivo starter, temperatura y período de incubación, la proporción del inóculo, y la producción del starter. El uso de equipos de desaireación de leche es altamente requerido para fermentación por bifidobacterias. La presencia de oxígeno en la leche puede prolongar el periodo de incubación.

\section{Tecnología de los cultivos estárter}

El tradicional sistema de repiques (Banco de cultivo-madre-alimentador o intermediario-paquetes) para propagación de cultivos estárter en la manufacturación de leches fermentadas, comenzó a ser desplazado por el sistema DVS (Direc Vat Set) (Tamine, et al, 1995).

Los cultivos comerciales DVS son adquiridos en forma de liofilizado concentrado o como cultivos concentrados mantenidos en congelación a $-196^{\circ} \mathrm{C}$, para posteriormente almacenarlos entre -40 y $-80{ }^{\circ} \mathrm{C}$, este tipo de cultivo puede ser conservado a temperaturas menores a $5^{\circ} \mathrm{C}$ hasta $-20{ }^{\circ} \mathrm{C}$, entre mas baja la temperatura, mayor será la extensión de la vida útil. La actividad de los cultivos depende de la taza de supervivencia, el recuento en promedio es mayor o igual a $10^{11} \mathrm{UFC} / \mathrm{g}$. Para lograr altos recuentos, las células bacterianas son concentradas antes de la preservación y almacenamiento. Los cultivos de bacterias probióticas altamente concentrados son 
usados como adjuntos dietarios para consumo directo, por ejemplo como tabletas farmacéuticas.

Existen diferentes métodos para ser usados en la concentración de biomasa de bacterias ácido lácticas, en el caso de bifidobacterias se utiliza la técnica de separadores mecánicos (tipo Sharples), neutralización del medio de crecimiento hasta pH 6,0 usando $\mathrm{NH}_{4} \mathrm{OH} 10 \mathrm{M}$ o NaOH $2 \mathrm{M}$ y ultrafiltración (UF) o microfiltración. Los cultivos pueden ser exitosamente conservados por liofilización o congelamiento a temperaturas bajas desde -10 a $-196{ }^{\circ} \mathrm{C}$. El congelamiento y/o el secado pueden causar daños en las células bacterianas, pero el uso de compuestos criogénicos (como leche descremada estéril, sacarosa, lactosa, gelatina, pectina, caseinato de sodio, alginato de sodio, glicerol y sorbitol) han ayudado a mantener la actividad de bifidobacterias. Factores como el recuento microbiano inicial antes de la conservación, el contenido de humedad en el cultivo liofilizado, el uso de compuestos de protección, el empaque bajo atmósferas controladas de $\mathrm{N}_{2}$, el uso de empaques impermeables al oxígeno y la temperatura de almacenamiento, influyen en la taza de supervivencia de los probióticos. Estudios de algunos autores encontraron que la mejor taza de supervivencia para especies de bifidobacteria se consiguió con la concentración por membrana de los cultivos y la adición de leche descremada (100 g/L) y sacarosa $(120 \mathrm{~g} / \mathrm{L})$ como material criogénico.

Otros estudios encontraron que un medio con base de suero de bajo costo, fue efectivo para el crecimiento de $\mathrm{B}$. bifidum en un proceso continuo de un reactor acoplado a una unidad de UF. Se obtuvo una buena viabilidad para los cultivos almacenados a $-4,-20$ y $-80{ }^{\circ} \mathrm{C}$, así como para los liofilizados.

\section{Preparación del inóculo}

En la patente USPat. 6,033,691, sugieren la preparación del inóculo de los microorganismos de la siguiente forma: Las cepas de Lactobacillus ssp y Bifidobacterium ssp son cultivadas en un medio con base de leche (o con el medio en que se requiera adaptar), previamente esterilizado, por ejemplo, a $90{ }^{\circ} \mathrm{C}$ por 5-6 minutos.

El producto esterilizado, es enfriado a $37{ }^{\circ} \mathrm{C}$ y adicionado de oligoelementos como hierro, cobalto y molibdeno, y de aditivos como biotina y aminoácidos, ajustando el $\mathrm{pH}$ entre 6,50 y 7,75. Las cepas de los lactobacilos son suspendidas en una solución fisiológica estéril e inoculadas. La incubación se realiza a $37{ }^{\circ} \mathrm{C}$ durante el período regulado por el recuento de la flora viable, usualmente entre $10^{5}$ y $10^{9} \mathrm{UFC} / \mathrm{mL}$. Durante el período de incubación es importante mantener el $\mathrm{pH}$ entre 6,30 y 6,60 a través del uso de soluciones tampón o ácidos y bases biocompatibles.

\section{Tamaño del inóculo}

Varios autores comentan acerca de cuanto debe ser el tamaño del inóculo, a continuación se enumeran algunos de las recomendaciones más usadas en el asunto en cuestión:

Los cultivos liofilizados de probióticos se aplican por medio de la técnica DVS (Direct Vat Set), es decir, directamente del paquete al medio de fermentación (Saarela, 2000). Rasic \& Kurmam (1983), comentan que los paquete con microorganismos probióticos liolizados que se comercializan actualmente son altamente concentrados. Los cultivos 
concentrados deben contener mínimo $5 \times 10^{9} \mathrm{UFC} \mathrm{g}^{-1}$, los no concentrados contienen hasta un máximo de $1 \times 10^{8} \mathrm{UFC} \mathrm{g}^{-1}$

Varman (1994) aconseja usar un alto nivel de inóculo, de 10-20\%, mientras que Dave \& Shah (1997), dicen que el incremento del nivel de inóculo no mejora la viabilidad de los probióticos.

Hansen (1985), basado en sus estudios recomienda usar 700-800 millones $\left(7-8 \times 10^{8}\right)$ de L. acidophilus $/ \mathrm{mL}$ y 400-500 millones de B. bifidum $/ \mathrm{mL}$. Inóculos menores a $10^{4}: 10^{3}$ (B.bifidum: L. acidophilus) suprimen el crecimiento.

\section{Reglamentación para productos con probióticos}

Rybka \& Kailasapathy (1995), estipula un número > $10^{7} \mathrm{UFC} / \mathrm{mL}$ para alcanzar un efecto terapéutico óptimo. Una persona puede llegar a consumir $10^{8}$ células de probióticos por día, el consumo regular de 400-500 g/semana de la bebida fermentada, conteniendo $10^{6}$ células viables por mililitro, puede suministrar ese número. El criterio de la NYA (Nacional Yogurt Association de los Estados Unidos) es de $10^{8} \mathrm{UFC} / \mathrm{g}$ de bacteria ácido láctico en el tiempo de la manufactura y después del embalaje. El reglamento de la Australian Food Standars Code, dice que los productos fermentados requieren $\mathrm{pH}$ de 4.5 o menor para prevenir el crecimiento de contaminantes patogénicos. (Lourens-Hattingh, 2001). Para que la bebida fermentada sea considerada un producto probiótico es necesario que las bacterias probióticas sobrevivan en el producto durante su vida de estantería. (Saxelin, et al., 1999). En el Japón se estableció una cantidad de oligosacáridos que suplemente el requerimiento de $0,8 \mathrm{~g} / \mathrm{kg}$ de peso corporal por día (Yun, 1996).

\section{Productos del mercado mundial con probióticos y prebióticos}

Desde la década pasada se ha presentado en Europa, Norteamérica y en muchos otros países un alto incremento en marcas de productos lácteos (fermentados o dulces) que contienen Bifidobacterias originarias de humanos. Cada producto fermentado es hecho usando un solo género, o en combinación con otras bacterias lácticas en forma de mixturas de cultivos estárter como se muestra en algunos ejemplos mas adelante (Tamine, A., Marshall, V. Robinson, R., 1995)

En las patentes de productos relacionados con probióticos y prebióticos, se reportan bebidas con leche de vaca u otros orígenes, productos deshidratados para uso farmacéutico o alimentación animal, así como combinaciones de probióticos para adición en diferentes tipos de alimentos de origen vegetal o animal (Tabla 2).

Tabla 2. Resumen de algunas patentes de productos relacionados con probióticos y prebióticos.

\begin{tabular}{l|l|l|l|c}
\hline \hline Número & \multicolumn{1}{|c|}{ Título } & $\begin{array}{c}\text { Fecha de } \\
\text { publicación }\end{array}$ & \multicolumn{1}{c|}{ Resumen } & Fuente \\
\hline \hline EP1186295 & $\begin{array}{l}\text { Préparations } \\
\text { pharmacutiques } \\
\text { contenant des } \\
\text { extraits } \\
\text { d'isoflavone de } \\
\text { soya et des } \\
\text { microorganismos } \\
\text { probióticos. }\end{array}$ & 2002-03-13 & $\begin{array}{l}\text { Preparación farmacéutica de extractos } \\
\text { de isoflavonas de la soya y los } \\
\text { microorganismos probióticos vivos, } \\
\text { como producto de la combinación, para } \\
\text { un suministro simultáneo o separado en } \\
\text { el tiempo, útil en el tratamiento de los } \\
\text { síntomas ligados a la menopausia. }\end{array}$ & \\
& & & \\
\hline
\end{tabular}




\begin{tabular}{|c|c|c|c|c|}
\hline FR2789854 & $\begin{array}{l}\text { Ice Cream } \\
\text { producr based on } \\
\text { fermented } \\
\text { soyamilk or } \\
\text { other vegetable }\end{array}$ & $2000-08-25$ & $\begin{array}{l}\text { Helado hecho con leche vegetal } \\
\text { fermentada, especialmente la leche de } \\
\text { soya y jarabe de cereal rico en glucosa. } \\
\text { Preparación: (a) preparación de leche } \\
\text { vegetal; (b) inoculación de la leche con } \\
\text { bateria láctica, preferiblemente } \\
\text { probiótica; (c) recuperación del } \\
\text { coagulado; (d)adición del jarabe de } \\
\text { cereal rico em glucosa; (e) } \\
\text { homogeneización de la mezcla; } \\
\text { (f)formación del helado. }\end{array}$ & esp@cenet \\
\hline FR2668683 & $\begin{array}{l}\text { Nutricional food } \\
\text { supplement for } \\
\text { force-fed } \\
\text { palmipeds }\end{array}$ & 1992-05-07 & $\begin{array}{l}\text { Consiste en harina de soya o arveja } \\
\text { mezclada com bicarbonato de sodio, } \\
\text { probióticos, vitaminas, minerales, } \\
\text { enzimas, suero y aminoácidos y llevado } \\
\text { en forma de ovoides masticables. El } \\
\text { producto de acuerdo con la invención } \\
\text { sirve como alimento fortificador de } \\
\text { palmípedos para producción de paté. }\end{array}$ & esp@cenet \\
\hline $6,254,900$ & $\begin{array}{l}\text { Method for the } \\
\text { manufacture of } \\
\text { cheese, quark } \\
\text { and yogurt } \\
\text { products from } \\
\text { soybeans }\end{array}$ & 2001-07-03 & $\begin{array}{l}\text { Incluye los siguientes pasos: (a) } \\
\text { preparación de la leche de soya; } \\
\text { (b)adición de azúcar vegetal; (c)adición } \\
\text { de grasas y aceites vegetales } \\
\text { emulsificantes en la leche de soya; (d) } \\
\text { preparación del cocktail de cultivo com } \\
\text { pH de } 3.8-4.5 . . .(e) \text { maduración final del } \\
\text { producto hasta obtener queso, quark y } \\
\text { yogurt. }\end{array}$ & USPatens \\
\hline $6,033,691$ & $\begin{array}{l}\text { Process for } \\
\text { manufacturing a } \\
\text { biologically } \\
\text { active fermented } \\
\text { milk product and } \\
\text { product obtained } \\
\text { by the process }\end{array}$ & 2000-03-07 & $\begin{array}{l}\text { Lactobacillus Casei (ATCC 55544) e } \\
\text { Lactobacillus Acidophilus (ATCC } \\
55543 \text { ) são simultáneamente } \\
\text { inoculados en leche previamente } \\
\text { adicionada com Streptococcus, y } \\
\text { después fermentado, resultando un } \\
\text { producto de leche activo } \\
\text { biológicamente. El producto puede ser } \\
\text { mantenido entre } 4-10 \mathrm{C} \text { por } 30 \text { dias. El } \\
\text { producto puede ser liofilizado y } \\
\text { mantenido a } 20-25{ }^{\circ} \mathrm{C} \text {, U.R. 40-60\% } \\
\text { por mínimo } 4 \text { meses. Al reconstituirse } \\
\text { consigue un pH cerca del líquido y es } \\
\text { palatable. }\end{array}$ & USPatens \\
\hline $5,895,648$ & $\begin{array}{l}\text { Composition for } \\
\text { feef use } \\
\text { comprising } \\
\text { lyophilized live } \\
\text { lactic bacteria }\end{array}$ & 1999-04-20 & $\begin{array}{l}\text { Compuesto de uso alimentario que } \\
\text { contiene una mezcla de bacterias vivas } \\
\text { liofilizadas comprendiendo por lo } \\
\text { menos dos especies de baterias } \\
\text { seleccionadas de Bifidobacterium } \\
\text { brevi, Bifidobacterium infantis, } \\
\text { Bifidobacterium longum } \\
\text { Bifidobacterium bifidum y por lo } \\
\text { menos dos especies de baterias } \\
\text { seleccionadas de Lactobacillus } \\
\text { acidophilus, Streptococcus } \\
\text { thermophilus, Lactobacillus bulgaricus, } \\
\text { Lactobacillus casei, lactobacillus } \\
\text { plantarum e Streptococcus faecium y } \\
\text { uno o más oligosacaridos. }\end{array}$ & USPatens \\
\hline
\end{tabular}




\begin{tabular}{l|l|l|l|l}
\hline \hline $5,922,375$ & $\begin{array}{l}\text { Probiotic } \\
\text { Bifidobacterium } \\
\text { strain }\end{array}$ & 1999-07-13 & $\begin{array}{l}\text { Especie de Bifidobacteium aislado USPatens } \\
\text { incorporado en alimentos, bebidas, } \\
\text { alimentos para animales e o } \\
\text { suplementos alimenticios. }\end{array}$ & \\
\hline
\end{tabular}

Las leches fermentadas son definidas como el producto de leche fermentada por la acción de microorganismos específicos, resultando en una reducción del $\mathrm{pH}$ y coagulación. Estos microorganismos específicos deben ser viables, activos y abundantes (no menor que $10^{7} \mathrm{UFC/g}$ ) en el producto en la fecha de mínima durabilidad (Ouwehand,A., 1998, Kurman,1992), pero no todos son probióticos.

Muchos productos contienen Bifidobacterias, B. bifidum y B. longum son altamente empleados como mezclas de cultivos estárter en combinación con L. acidophilus y cultivos de yogurt (L. delbrueckii subsp. bulgaricus y/o Streptococcuus salivarus subsp. thermophilus). En algunos casos Lactococcus ssp. y Pediococcus acidilactici también son usados. Alimentos y bebidas como Yakult ${ }^{\circledR}$ (Japón), Biogurt ${ }^{\circledR}$ (Alemania), Biokys ${ }^{\circledR}$ (Rep. Checa), Mil-Mil ${ }^{\circledR}$ (Japón), AKTIFIT plus ${ }^{\circledR}$ (Suiza), Ofilus ${ }^{\circledR}$ (Francia), Philus (Suecia), BA live (Inglaterra), A - 38 (Dinamarca), Zabadi (egipto) entre otros contienen probióticos (Lactobacillus ssp e Bifidobacterium ssp) y se comercializan en el mundo.

\section{Futuros Desarrollos e Investigaciones}

La investigación en el campo de los probióticos y prebióticos todavía tiene muchas posibilidades de estudios, dirigidos a su mejor conocimiento, incremento de su supervivencia en diferentes medios o condiciones de proceso, facilitar su acceso en diferentes mercados, facilitar su manipulación en la manufactura de productos y lograr efectos positivos en nutrición-salud humana cada vez mayores. Varios autores como Salminen et al. (1999), Tamine et.al.(1995), Saarela et al. (2000), entre otros coinciden en que las futuras invesitgaciones en el campo de los probióticos son:

La interconexión entre los conocimientos de expertos y científicos en alimentos, con el funcionamiento del tracto gastrointestinal y la salud humana.

Estudiar los mecanismos de acción de los probióticos en el tracto gastro-intestinal, y el desarrollo de herramientas de diagnóstico y biomercadeo.

La evaluación del papel de los probióticos en la salud de grupos de consumidores.

Direccionar aspectos específicos relacionados con los consumidores y la comercialización de productos funcionales.

Asegurar la estabilidad y viabilidad de productos probióticos por tecnologías de punta (p.e. bioencapsulación).

Desarrollar tecnologías para aplicaciones de probióticos en productos no lácteos. Selección de especies susceptibles y con capacidad de fermentación de leche y otros sustratos. 
Manipulación genética, si fuera posible, para mejorar el crecimiento en leches de las bifidobacterias y reducir la alta producción de ácido acético.

Debido a que los resultados in vitro no siempre se han relacionado con las pruebas in vivo, o los resultados con experimentos en animales no siempre son aplicables en humanos, se sugiere implementar diseños experimentales que envuelvan pruebas con humanos voluntarios.

Mayor intervención del área médica en estudios sobre los efectos benéficos de microorganismos terapéuticos.

Desarrollo de cultivos estárter que no dependan de otros y que inhiban el crecimiento de microorganismos indeseables.

Necesidad de más metodologías para desarrollar la caracterización de la microflora intestinal, incluyendo especies no cultivables.

Importancia de la viabilidad

Fenómenos de comportamiento de probióticos en combinación o no con otras especies o con sustancias promotoras de crecimiento como los prebióticos, para lograr efectos simbióticos.

La bioingeniería y biotecnología de producción: estudios de cinéticas y determinación de parámetros cinéticos que permitan mejoras en las aplicaciones tecnológicas.

Ampliar los estudios relacionados con prebióticos, especialmente en la obtención de frutooligosacáridos, en la obtención de mayores rendimientos de producción, hallazgo de nuevas especies o fuentes de enzimas para síntesis.

Así como su efecto sobre los diferentes probióticos, preparaciones simbióticas y efectos sobre la salud.

\section{Conclusiones}

Actualmente existe la necesidad de ofrecer al mercado nuevos productos funcionales y nutracéuticos, que complementen algunos requerimientos nutricionales y que aporten los beneficios que presentan los probióticos y prebióticos en el mantenimiento del balance de la microflora intestinal, la reducción de problemas intestinales como la mala absorción de la lactosa o la protección contra infecciones y la prevención de algunas enfermedades relacionas con la digestión.

La integración de grupos multidisciplinarios para la investigación y desarrollo de productos funcionales y nutracéuticos que involucren probióticos y prebióticos se hace indispensable hoy en día, pues existe una conciencia mayor por parte de la población para el consumo de alimentos más saludables y nutritivos; también, para contribuir con el objetivo general de promoción de la salud, disminución de la desnutrición y malnutrición humana, y el ofrecimiento de alternativas alimenticias para la población con necesidades específicas de nutrición. 


\section{Bibliografía}

[D] Alves, F.V. Síntese de Oligossacarídeos por inulinase em meio orgânico. Campinas, 2002. Tese de Doutorado (em andamento) - Faculdade de Engenharia de Alimentos, Universidade Estadual de Campinas.

[C] Applicant No. 195006. Hansen; Wilhem.(1998). Method for the manufacture of cheese, quark and yogurt products from soybeans. USPatens 6,254,900, 18 nov. 1998, 3 jul 2001.

[D] Carvalho,Gabriel. Nutrição, probióticos e Disbiose. Nutrição, Saúde \& performance, ano 3, n.14, p. 36-37, 2001

[D] Dave, R.I.,\& SHAH, N.P. Ingredient supplementation effects on viability of probiotic bactéria in yogurt. Journal of Dairy Science. v. 81, p. 2804-2816. 1997

[L] Ferreira, Célia L.L., TESHIMA, Elisa. Prebióticos, estratégia dietética para a manutenção da microbiota colônica desejável. Revista Biotecnologia Ciência \& Desenvolvimento. ano III -n. 16 - set./out. p. 22-25, 2000.

[d] Fooks, L. J.; Fuller, R.; Gibson, G. R. Prebiotics, probiotics and human gut microbiology. International Dairy journal. v.9, p.53-61, 1999.

[C] Fuller, R. (1989). Probiotics in man and animals. Journal or applied Bacteriology. v. 66, p. 365-378,1989. Ibid: International dairy journal. v. 11, p. 1-17, 2001.

[D] GIBSON, G. R. and Roberfroid, M.B. Dietary and modulation of human Colonic Microbiota: Introducing the concept of Prebiotics. J. Nutr. v. 125, p.1401-1412, 1995. Ibid Trends in Food Science \& Technology. v. 9, p. 295-306, 1998

[D] Gimenez P., Mariana Alessandra. Efeito do teor de lactose e do tipo de cultura na acidificação e pós-acidificação de iogures. Campinas, 2002. Dissertação (Mestrado em Engenharia de Alimentos). Faculdade de Engenharia de Alimentos. Universidade Estadual de Campinas. 86 p.

[C] Guillilan, S.E. \& Speak, M. L. Antagonistic action of L. acidophilus toward intestinal and food-borne pathogens in associative cultures. Journal of food protection. v. 40(11) p.820-823, 1977.

[D] HANSEN, R. Bifidobacteria have come to stay. North European Dairy Journal. v. 3. p. 1-6. 1985.

[Dal Hansen; W. Method for the manufacture of cheese, quark and yogurt products from soybeans. APPLICANT No. 195006. USPatens 6,254,900, 18 nov. 1998, 3 jul 2001.

[D] Knorr, Dietrich. Technology aspects related to microoganisms in functional foods. Trends in Food Science \& Technology. v. 9, p. 295-306, 1998

[D] Kurman, Joseph A., Rasic, Jeremija. Encyclopedia of fermented fresh milk products. New York: Van Nostrand Reinhold., 1992. p.306-307

[C] Laboratoires dolisos, Pierre Fabre; René Belle; Bernard Fabre. (2002). Préparations pharmacutiques contenant des extraits d'isoflavone de soya et des microorganismos probióticos. FR. n. EP1186295A1. 31 ago 2001, 13 mar 2002. Office européen des brevets. esp@cenet database

[D] Le Soyami Soc (FR). Garreau Jean. James. Ice Cream product based on fermented soymilk or other vegetable. FR 2789854, 25 ago 2000. esp@ cenet database

[D] Lourens-Hattingh, A.;Viljoen, B. C. Yogurt as probiotic carrier food. International dairy journal. v. 11, p. 1-17, 2001.

D. Mc. Cartney, Wenzhi and Tannock. Molecular analysis of the composition of the bifidobacterial and lactobacillus microflora of human. Applied and environmental 
Microbiology,62,4608-4613, 1996. Ibid: International dairy journal. v. 9, p. 53-61, 1999.

[D] Ouwehand, Arthur, Salminen J. The health effects of cultured milk products with viavel and não viavel bacteria. International Dairy Journal. v. 8, p. 749-758, 1998

[C] Pinheiro, Andrelina S. Síntese de oligossacarídeos por inulinase de Kluyverimyces marxianus var. bulgaricus. Campinas, 2002. Tese (Doutor em Engenharia de Alimentos). Faculdade de Engenharia de Alimentos. Universidade Estadual de Campinas.

[D] Ponconnet Eric, Eric Ponconnet. Nutricional food supplement for force-fed palmipeds. FR 2668683. 7 mayo 1992. esp@cenet database .

[D] RASIC, J.L. Culture media for detection and enumeration of bifidobacteria in fermented milk products. IDF bulletin, v. 252, p. 22-48, 1990. Ibid International dairy journal. v. 11, p. 1-17, 2001.

[D] Ribka, S. \& Kailasapathy, K. The suvirval of culture bacteria in fresh and freezedryed AB yoghurts. The Australian Journal of Dairy Technology. v. 50(2), p. 5157, 1995.

Roberfroid, M. (2000). Prebiotics and probiotics: are they functional foods?. Am.J Clin Nutr 71(suppl):1682S-7S.

미 Saarela, M; Mogensen, G.; Fondén, R.; Mättö, J.; Mattila-Sandholm, T. Probiotic bactéria: safety, functional and technological properties. Journal of Biotechnology. v. 84, p. 197-215, 2000.

미 Salminen, S,. Ouwehand, A. Probiotics: how shold they be define?. Food science \& technology. v.10, p. 107-110, 1999.

[Dd Sancor Cooperativas Unidas Limitada. Ricardo Alberto Cravero. Process for manufacturing a biologically active fermented milk product and product obtained by the process. USPatens 6,033,691, 17 sept. 1998, 7 mar. 2000.

[D] Saxelin, M. (1999).The technology of probiotics. Food science and technology 10, 387-392, 1999.

[C] Scalabrini, P., Rossi, M., Spettoli, P., \& Matteuzzi, D. Characterization of Bifidobacterium stains for use in soymilk fermentation. International Journal or Food Microbiology. v. 39. p. 213-219.1998

[Dal Sitia-Yomo S.p.A. Cavaliere Vesely; Renata; Giani; Giovanni; Maiocchi; Gianluigi, Vesely; Marco Emilio; Leonardo.Composition for feef use comprising lyophilized live lactic bacteria. USPatens 5,895,648, 3 sept. 1997, 20 abr. 1999.

Tamine, A., Marshall, V. Robinson, R. Microbiological and technological aspects of milks fermented by bifidobacteria. Journal of Dairy Research. v. 62 p. 151-187, 1995.

[D] Tamine Y. \& Robinson,R. Yogurt science and technology. Cambridge: Woodhead Publishing Limited. Second edition. 2001.p.358-359,366-367.

[Dd Tamine, Y.\& Robinson, R. Yogurt ciencia y tecnologia. Zaragoza: Editorial Acribia S.A. 1991.368 p..

[C] Universidade Estadual De Campinas. Francisco Maugeri Filho; Andrelina Maria Pinheiro Santos. Produção de xarope de açúcar contendo frutose e glicose, enriquecido ou não com frutooligossacarídeos, a partir de sacarose. BR. Pedido de patente PI0202602-3, 28 fev 2002.

[Dd Varman, A. H. \& Sutherland, J. P. Milk and milk products. London: Capman and Hall. 1994. p 347-380. 
[D] Vindelora, C. G.; Reinheimer, J. A.Enumeration of Lactobacillus casei in the presence of L. acidophilus, bifidobacteria and starter bacteria in fermented dairy products. International Dairy Journal. v. 10, p. 271-275, 2000.

[D] Vindelora, C. G.; Reinheimer, J. A. Culture media for the enumeration of Bifidobacterium bifidum and Lactobacillus acidophilus in presence of yoghurt bacteria. International Dairy Journal. v. 9, p. 497-505, 1999.

[C] Wisconsin Alumni Research Foundation. John B. Luchansky. Probiotic Bifidobacterium strain. USPatens 5,922,375, 25 nov. 1998, 13 jul. 1999.

[D] Yun, J. W. Fructooligosaccharides-Occurrence, preparations, and application. Enzyme and Microbial Technology. v. 19, p. 107-117, 1996. 